\title{
Estimation of bedrock depth for a part of Garhwal Himalayas using two different geophysical techniques
}

\author{
Ritu Raj Nath* (1), Gautam Kumar, M. L. Sharma and S. C. Gupta
}

\begin{abstract}
It has now been well established that the depth of bedrock is a key parameter in assessing the impact of local site conditions on seismic hazard analysis. Where conventional geotechnical testing like standard penetration test (SPT) or cone penetration test (CPT) requires a far greater cost and manpower to be used for such purposes, geophysical testing like ground-penetrating radar (GPR) and multichannel analysis of surface waves (MASW) may provide the researchers with more viable options to achieve conclusive evidence on bedrock depth. Application of geophysical techniques has become more and more extensive and advanced in many geo-morphological studies since the early 2000s. Geophysical techniques require less time and effort, and the easy processing of the obtained data is the primary reason for their popularity. However, due to variability in subsoil mechanical properties, wave attenuation and dispersion and diverse geological boundary conditions, the results obtained through geophysical techniques are often ambiguous and non-unique. The interpretation of the obtained data also requires skill and experience, as the range may vary widely and more often than not consensus is difficult to achieve. In this paper, an endeavor has been made to coalesce the results of two widely used geophysical techniques, namely GPR and MASW to derive more conclusive evidence for the detection of bedrock depth in a part of Garhwal Himalayas. The study area comprises of two different cities of Uttarakhand, India. Both the sites possess different geo-morphological attributes and thus prove to be a perfect platform to conduct the experimentations. Both GPR and MASW testing have been performed and results are shown in graphical format. A comparison of the GPR survey with a conventional geotechnical testing (SPT) is also presented here. This study shows that GPR and MASW can provide complementary results in estimating bedrock depth.
\end{abstract}

Keywords: Seismic hazard, Wave attenuation, Subsurface geology, Ground-penetrating radar, Multichannel analysis of surface waves, Bedrock depth

\section{Background}

The influence of local site conditions on amplification of strong ground motion has been widely recognized. Several examples from the past (e.g., 1985 Mexico earthquake, 1989 Loma Pieta earthquake, 2001 Bhuj earthquake) have demonstrated that local site conditions play a substantial role in the performance of the structures during a major earthquake. It is now a wellaccepted fact that the depth of bedrock significantly

\footnotetext{
*Correspondence: riturajnath14@gmail.com

Department of Earthquake Engineering, IT Roorkee, Roorkee 247667, India
}

alters the dynamics of the system as a whole (Nath and Jakka 2012). Hence, it is preferred to estimate the depth of bedrock as accurately as possible considering its implication on seismic hazard analysis (Bard 1995; Boore 2004; Nath et al. 2015). However, if the conventional methods of geotechnical exploration down to the bedrock level are to be employed for such studies, one has to face some very stiff challenges in terms of both cost involved and manpower required. With the advent of various geophysical methods as a tool to explore subsurface geology, seismologists and engineers have begun to venture this challenging terrain. As pointed out by Van Dam (2012), geophysical techniques require less time and effort, and 
the easy processing of the obtained data are the primary factors behind their popularity. The proliferation in technical innovation as computers, software technology and light weight equipments also influence the increasing interest in geophysical explorations. Many researchers focus on the use of the geophysical application in fossil fuel exploration, existence of minerals and detection of underground water level. Of late, the use of geophysical methods become sustainable and functional in the field of permafrost mapping, block field, sediment thickness, depth and internal structures of landslides (Hauck 2001; Schrott 2002; Israil and Pachauri 2003; SchSrott et al. 2003; Bichler et al. 2004; Sass 2007).

However, due to variability in subsoil mechanical properties, wave attenuation and dispersion and different geological boundary conditions, the results obtained through geophysical techniques are often ambiguous and non-unique. The interpretation of the obtained data requires skill and experience, as the range may vary widely and more often than not consensus is difficult to achieve. Schrott and Saas (2007) have recommended the use of two or more geophysical methods to reach a strong conclusion, rather than a single method. The study has focused on the development of a set of most favorable conditions for combining different geophysical techniques. Although studies on combined application of two or more geophysical techniques are becoming popular nowadays (Pilecki et al. 2017), there has not been much combined studies carried on estimation of bedrock depth, especially for the Garhwal Himalayan region. The whole Himalayan arc has always been seismically very active and produced several catastrophic earthquakes (1897 Assam, 1905 Kangra, 1934 Bihar-Nepal, 1950 Assam, 1991 Uttarkashi, 1999 Chamoli) and many smallto medium-scale earthquakes in the past (Nath and Thingbaijam 2012). Therefore, it is of paramount importance to comprehend the local site conditions of the area: both qualitatively and quantitatively. In this paper, an attempt has been made to combine the results of two widely used geophysical techniques, namely GPR and MASW, for estimation of the bedrock depth in a part of Garhwal Himalayas. The study shows that both geophysical techniques produce results which are more or less complementary in nature and thus can be used to have a better engineering insight.

\section{Study area}

For the present study, two sites in the state of Uttarakhand, India, were selected. The first site of the study area is the Santura Devi temple of Mussoorie, a famous hill station of Dehradun District. The study area and its environs exhibit geological similarities with the northern limb of the Mussoorie Syncline. Sedimentary rocks, typically Krol and Blaini formation of the Lesser Himalaya shape this landscape, with dolomitic limestone and shales being the most common types (Pal et al. 2012). Near vertical discontinuities mark the highly jointed and fractured rock mass. The key criterion for selection of this site is its proximity to the main boundary thrust (MBT) due to which the level of seismic hazard is very high here.

The second site in the study area is the Mansadevi landslide of Haridwar District. By selecting a landslide, the utility of GPR and MASW in landslide studies could also be evaluated and this motivates the site selection criterion here. The lithology of the area comprises conglomerate, sandstone and mudstone sequence of Pliocene to early Pleistocene age. They belong to middle to upper Siwalik group with sedimentary formation (Mittal et al. 2008). The landslide has been affected by severe tectonic movement along the Main Frontal Thrust, Ganga Tear Fault, and several minor faults located in its vicinity. The presence of a shear zone in the area is felt by the nature of material yielding, most commonly observed as breaking off, toppling and/or sliding of mudstone or sandstone. The general and geo-morphological attributes of the study area are presented by Fig. 1a, b below. The tectonic setup of the study area has been studied quite extensively and is easily available (Joshi and Mohan 2010; Patil et al. 2014).

Both the sites selected for the study possess different geomorphologic attributes and bedrock is expected to be at different depths for each site. Thus, it provides a perfect platform to conduct such study.

\section{Ground-penetrating radar (GPR)}

GPR is a very useful noninvasive, nondestructive geophysical tool primarily used for subsurface imaging. GPR gives result with high resolution at shallow depth up to 0-10 m. It may be used to explore even greater depth up to $50 \mathrm{~m}$, but the accuracy and resolution will be compromised. It mainly works on the principle of dielectric constant. Below the earth surface there exists various soil layers with different dielectric constants. Soil layers with higher dielectric constant will have lower electromagnetic wave velocity and vice versa. GPR contains antennas of varying frequencies, ranging between $10 \mathrm{MHz}$ and $4 \mathrm{GHz}$. The penetration depth of the electromagnetic wave depends on the frequency of the antenna. GPR can either be used in reflection or transmission modes. The reflection profiling survey method is the most common and is normally conducted using two antennae (called the bi-static mode), with a separate transmitter and receiver. These antennae are placed directly on, or relatively close to, the ground surface to be measured. The antennae may also be mounted on a wheeled trolley or 
a

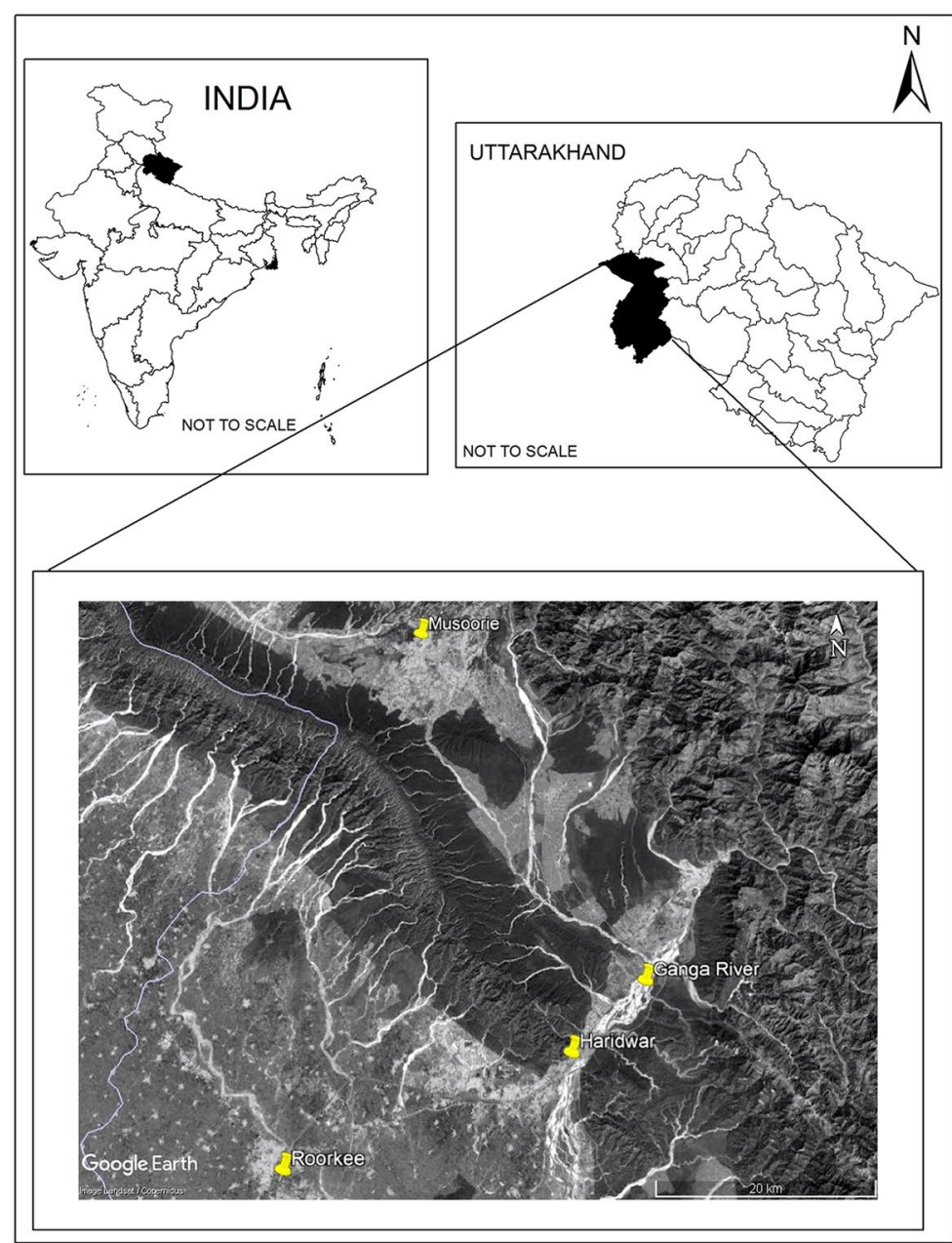

b

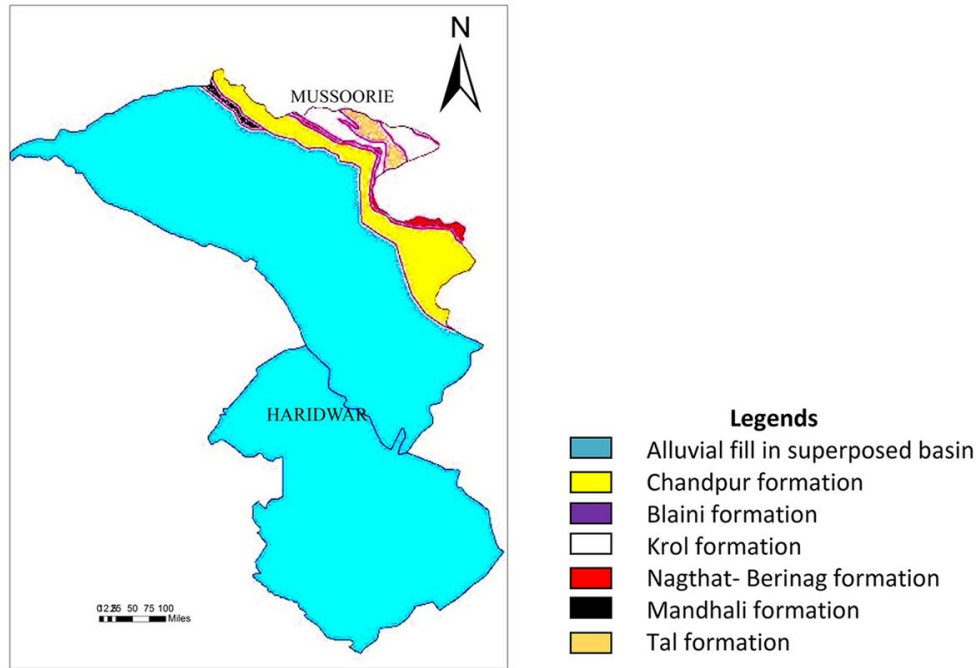

Fig. 1 The study area with $\mathbf{a}$ geo-morphological features and $\mathbf{b}$ geological features 
sled to protect the equipment and to speed up the survey. Although Bristow and Jol (2003) have observed that $100 \mathrm{MHz}$ antenna provides the best trade-off between depth of penetration and resolution of the image, after a sensitivity analysis at the site, lower-frequency antennas of 80 and $35 \mathrm{MHz}$ have been used here considering that the main objective of the study is to estimate the bedrock depth. Sass (2007) has carried out an extensive study to measure the sediment thickness of alpine talus slopes using three different geophysical techniques (GPR, 2-D resistivity and seismic refraction) and observed that the combined application of two or three techniques had improved data interpretation.

The range and resolution of GPR results mainly depend on sediment mineralogy and GPR antenna frequency (Motoyuki 2001). The main limitation of GPR lies in its incapability to provide any information on either index properties or mechanical properties of the subsurface geology. As the penetration depth of electromagnetic waves depends on electrical resistivity and conductivity of soil, the moisture content of the soil greatly influences the results of GPR. Figure 2 shows a typical set of GPR testing conducted at a particular site in the study. The system has five main components: (i) control unit, (ii) transmitter, (iii) receiver, (iv) antennae and (v) interface, data storage and display module. Data were transferred from the antennae to the control unit through fiber-optic cables. Automatic gain control (AGC) was applied as it is the best way of acquiring data (Neal 2004). Data were collected by point to point mode of survey, and a sensitivity analysis was performed beforehand to decide the optimum antenna frequency to be used for that site, step size and the antenna separation distance. Collected data were processed as described by Fisher et al. (2000), using GPR Manual Version 7.0 supplied by Geophysical Survey System Instruments (GSSI), with GSSI computer-based RADAN software by applying infinite impulse response (IIR), finite impulse response (FIR) filters, 2-D spatial fast Fourier transform filters, gain control, surface normalization, de-convolution, band pass filtering and hyperbola migration.

\section{Multichannel analysis of surface waves (MASW)}

MASW method is a surface wave technique for estimation of dynamic soil properties of the underlying soil strata using the dispersive characteristics of surface waves in layered media (Park et al. 1999). For this technique, a linear array of geophones is used to record vertical components of the vibration generated at one end of the array. The phase difference between records of different sensors is calculated for all frequencies which in turn provide the phase velocity of that frequency, as the distance between the sensors is known.

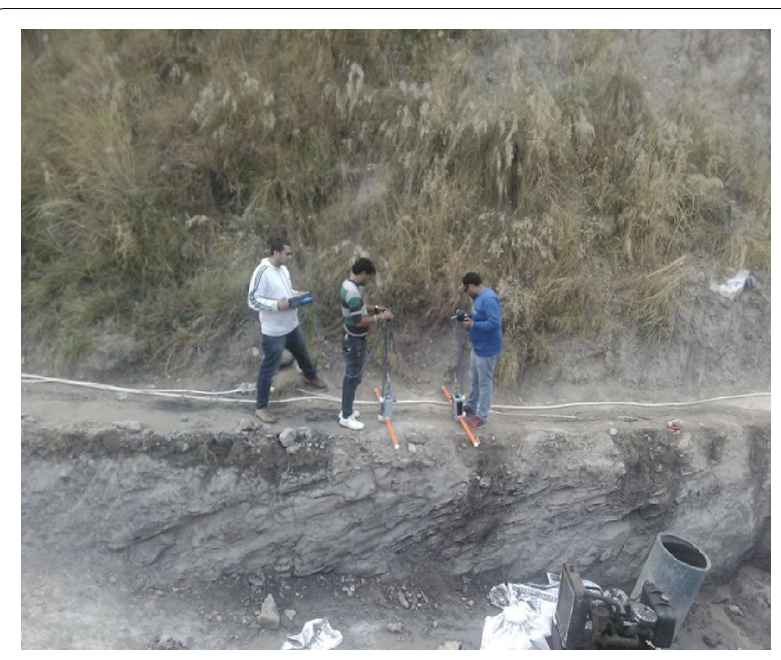

Fig. 2 A typical set of GPR testing conducted at Mansadevi landslide

Using this method shear wave velocity profiles can be estimated down to several tens of meters. The choice of equipment and testing configuration is closely linked to the scope of the test and the technique to be used in the interpretation. Sitharam (2006) carried out an MASW survey and concluded that MASW can be effectively used for the soil layer profiling and identification of rock depth and measurement of dynamic properties. Mahajan et al. (2011) have conducted studies on characterization of sediments in the Himalayan foothills using both active and passive MASW techniques. More recently, Pandey et al. (2016) carried out extensive MASW studies for quantifying the influence of local site conditions on strong ground motions. MASW is a well-accepted and widely used method for seismic microzonation studies.

For conducting MASW testing, equipment known as McSeis-SXW, manufactured by OYO Corporation Japan, was used. The geophones used were of $2 \mathrm{~Hz}$ frequency and an $80-\mathrm{kg}$ drop weight hammer was used as the source. After finalizing the location, an array of 24 geophones of $2 \mathrm{~Hz}$ frequency was laid out at the spacing of $2 \mathrm{~m}$. The geophones were connected to the data acquisition device. The "2-D surface wave method" was opted in the data acquisition device for conducting the required survey. The drop weight hammer was placed at $2 \mathrm{~m}$ intervals for each shot. The starting location was $1 \mathrm{~m}$ prior to the first sensor in the line of sensors. The last location was $1 \mathrm{~m}$ away from the last sensor in the line of sensors. Hence, a total of 25 shots were recorded for each station. The data recorded in 25 shots were then analyzed using the software SeisImager/SW. The SeisImager/SW software has three more tools, i.e., PickWin95, WaveEq and GeoPlot, which are used for further analysis. A detailed description of the procedure is not provided here due to paucity of both scope and space. 


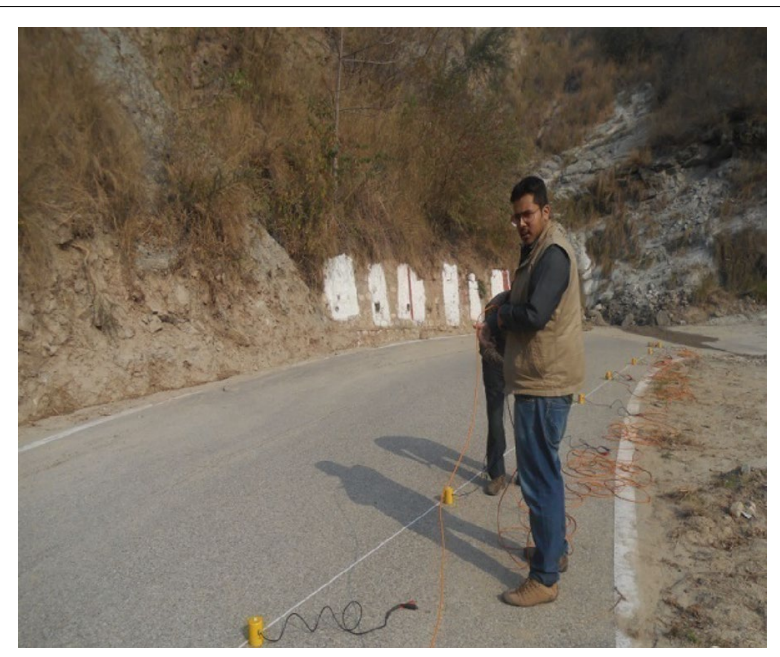

Fig. 3 A typical set of MASW testing conducted at Mansadevi landslide

Figure 3 shows a typical set of MASW testing conducted at a particular site in the study.

\section{Validation of GPR results}

It is widely acknowledged that the uncertainties associated with any geophysical exploration is quite high and hence it is imperative that any data obtained through geophysical exploration should be weighed against those obtained through a geotechnical investigation. Therefore, a study was carried out beforehand to validate the data obtained from GPR against conventional standard penetration test (SPT). For this purpose, Roorkee, Uttarakhand, India, was selected. SPT was conducted at numerous places in and around this site and those data are easily available. A very thick layer of alluvial sedimentary deposit underlines the bedrock here. The lithology of the area comprises cyclic sequence of gray micaceous sand, silt and clay/brownish gray clay, sand and gravel with boulders of Quaternary age. The soil here is mostly poorly graded. Table 1 shows

Table 1 Results of a standard penetration test at Roorkee City (Muzammil 2013)

\begin{tabular}{lrlll}
\hline Depth (m) & $\boldsymbol{N}$ & $\begin{array}{l}\text { Dry density } \\
\text { (gm/cc) }\end{array}$ & $\begin{array}{l}\text { Corrected } \boldsymbol{N} \text { for over } \\
\text { burden pressure }\end{array}$ & Soil type \\
\hline .75 & 11 & 1.53 & 19.01 & $\mathrm{SP}$ \\
1.5 & 8 & 1.52 & 7.41 & $\mathrm{SP}$ \\
3.0 & 7 & 1.52 & 6.09 & $\mathrm{CL}$ \\
4.5 & 11 & 1.59 & 8.99 & $\mathrm{CL}$ \\
6.0 & 5 & 1.60 & 3.87 & $\mathrm{CL}$ \\
7.5 & 17 & 1.63 & 12.47 & $\mathrm{SP}$ \\
9.0 & 11 & 1.63 & 7.69 & $\mathrm{SP}$ \\
\hline
\end{tabular}

$S P$ poorly graded sand, $C L$ lean clay or clay of low plasticity the results of one such SPT for a particular site at which a GPR survey was performed.

The results show that three distinct soil layers are present up to $9.0 \mathrm{~m}$ of depth at this site. Following laboratory testing, the types of soil were determined as poorly graded sand (SP) and lean clay or clay of low plasticity (CL).

The results of GPR survey are shown in Fig. 4. GPR provides information up to a depth of $17.5 \mathrm{~m}$ belowground level with three distinct soil layers of different thickness. Demarking the ground level at $0 \mathrm{~m}$ height, the first layer extends up to $2 \mathrm{~m}$. Similarly, the second and the third layers are marked at $7 \mathrm{~m}$ (a total thickness of $5 \mathrm{~m}$ ) and $14 \mathrm{~m}$ (a total thickness of $7 \mathrm{~m}$ ), respectively. These results show excellent concurrence to the SPT data obtained and hence can be used to validate the use of GPR for subsurface exploration. However, GPR does not reveal any mechanical or index properties of the layers, which is a big limitation of the technique. Therefore, combining the results of the both geotechnical and geophysical investigations, different soil types are determined as shown in Fig. 4.

Moreover, the GPR data shows a gentle slope from 7 to $10 \mathrm{~m}$ depth, which was not revealed during SPT. However, it is to be understood that GPR does not work as well in conductive/clay-rich environments, due to signal attenuation. With this in mind, it is possible that the sloping layer of Fig. 4 could be the tail of a diffraction hyperbolae, and therefore an artifact from above ground rather than a true subsurface feature. Although with GPR, up to $17 \mathrm{~m}$ depth has been explored, it is very difficult to process the data obtained below $14 \mathrm{~m}$ depth. This may be attributed to scattering and dispersion of EM waves below that depth. It is understood that for deep alluvial soil deposits, GPR is not solely sufficient for subsurface

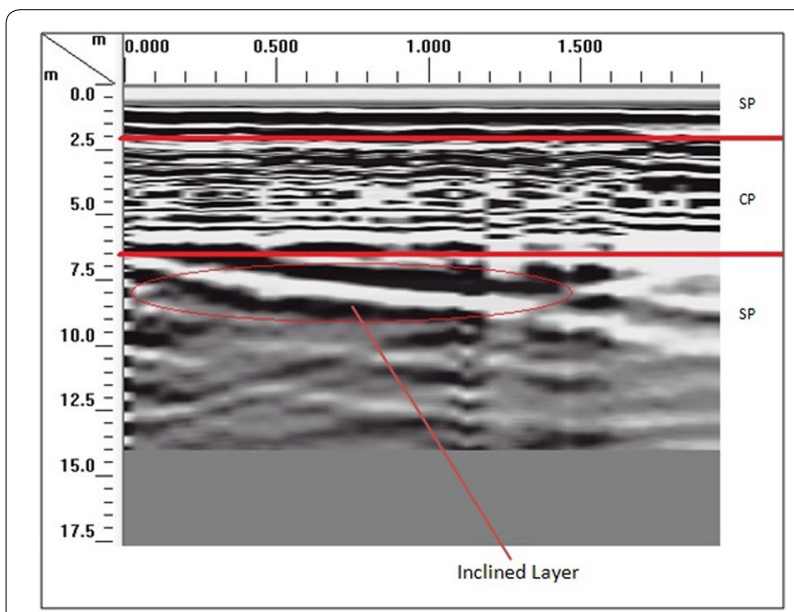

Fig. 4 GPR results for Roorkee using $35 \mathrm{MHz}$ antenna (SP poorly graded sand; CL lean clay or clay of low plasticity) 
exploration. It gives an idea about the boundary conditions where dielectric constants change with different material properties. Using sound engineering judgment, this information can be effectively maneuvered in deciding the thickness of subsurface layering.

\section{Estimation of bedrock depth: results and discussion}

\section{Santura Devi temple area, Mussoorie, Uttarakhand}

To estimate the bedrock depth, both GPR and MASW experiments were carried out at the first site of the study area. For the GPR survey, 80 and $35 \mathrm{MHz}$ frequency antenna were used. Data were collected in bi-static staking (point) mode of survey. The results of the GPR survey have been shown in Fig. 5a, b. While $80 \mathrm{MHz}$ frequency antenna provides higher resolution, it delivers information only up to a depth of $17.5 \mathrm{~m}$. So, $35 \mathrm{MHz}$ frequency antenna was used to explore greater depth. Approximately, $35 \mathrm{~m}$ of subsurface depth was imaged, although resolution was compromised. As the aim of the study is to locate the bedrock, the resolution provided by the $35 \mathrm{MHz}$ antenna is considered to be sufficient here. Both profiles were taken along the same line, but in the reverse direction. As it is a well known fact that GPR results do not provide any information on mechanical and/or index properties of the subsurface geology, the different layers shown in the results are assumed based on visual inspection of the structural discontinuities in the recorded images. The parallel reflectors at the top of Fig. $5 \mathrm{a}$ from the surface to $1 \mathrm{~m}$ depth form the first layer. It is followed by a layer of hummocky reflectors with $2 \mathrm{~m}$ depth which constitutes the second layer. Thus from the surface down to $3 \mathrm{~m}$ depth, two subsurface layers have been assumed. From 3 to $17.5 \mathrm{~m}$ parallel reflectors could be observed which form the next layer. Within this layer, one can observe an inclined layer clearly. While arguments could be made that this layer inclination is the tail of a diffraction hyperbolae, and therefore an artifact from aboveground rather than a true subsurface feature; the topography of the survey site would suggest otherwise (the survey was carried out on a slope itself). Hence, we would like to believe that it is indeed a subsurface feature which will be further discussed in the MASW section. Similarly for Fig. 5b, three geological layers have been assumed based on the characteristics of the reflectors. Bedrock is estimated to be located around $\sim 24 \mathrm{~m}$ from the ground surface. Two layers of soil strata exist at the depth range $0-3 \mathrm{~m}$ and 3-24 $\mathrm{m}$. In between 3 and $19 \mathrm{~m}$, another inclined layer has been detected. Below $24 \mathrm{~m}$ depth, there is a zone of signal attenuation, which is later assessed to be the bedrock with the support of MASW data.

The shear wave velocity profile of the same was then obtained using an MASW setup (Fig. 6). Table 2 summarizes the results of the MASW experiments at the site.

Shear wave velocity $\left(V_{\mathrm{s}}\right)$ actually represents the velocity with which earthquake shear wave will propagate through a material of interest, often soil and rock. The significance of shear wave velocity lies in the fact that it is directly proportional to shear modulus $(G)$ of soil/rock, a dynamic property. Thus, estimating the shear wave velocity profile at a particular site becomes the first step in assessing the local site conditions prevailing at that site, as it gives a very clear picture of the stiffness of different layers. In most of the seismic hazard analysis, engineering bedrock is defined as the layer where $V_{\mathrm{s}} \geq 760 \mathrm{~m} / \mathrm{s}$
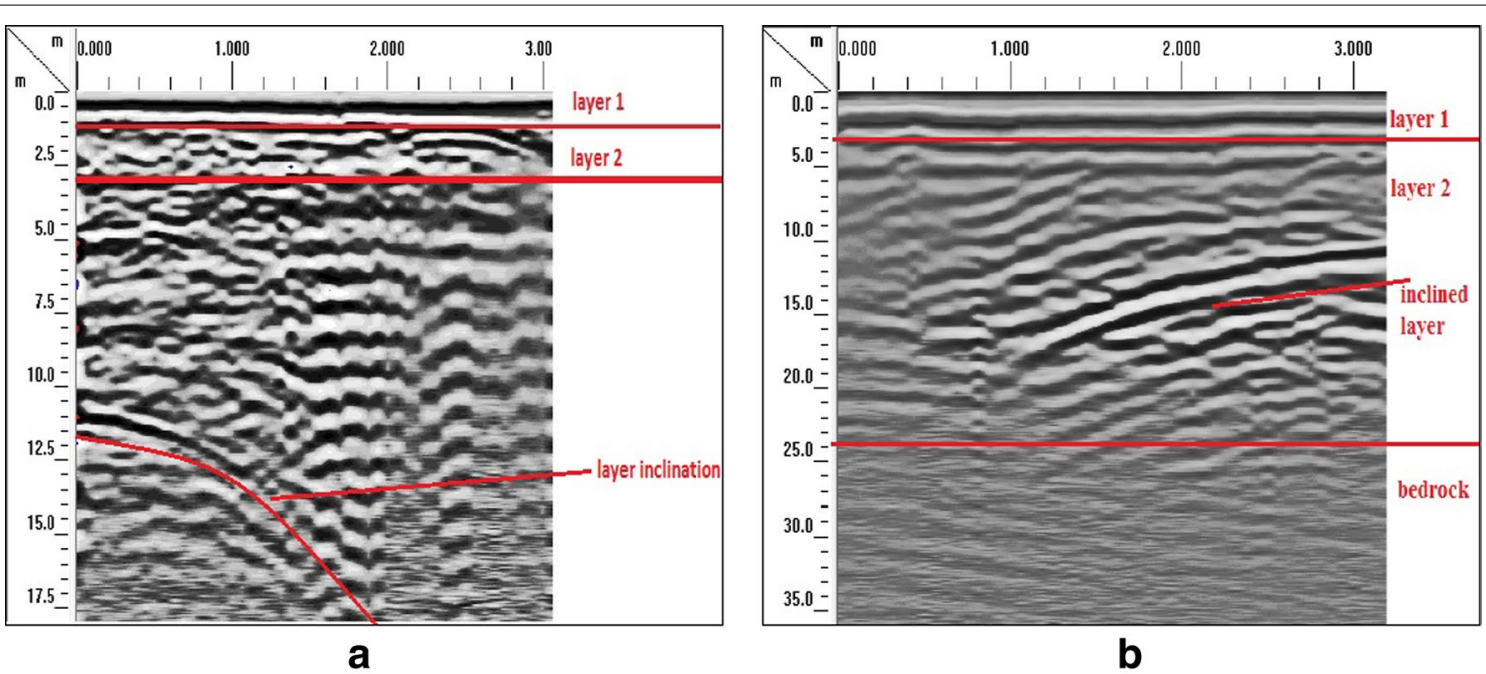

Fig. 5 GPR results at Santura Devi temple area, Mussoorie with a $80 \mathrm{MHz}$ and b $35 \mathrm{MHz}$ antenna 


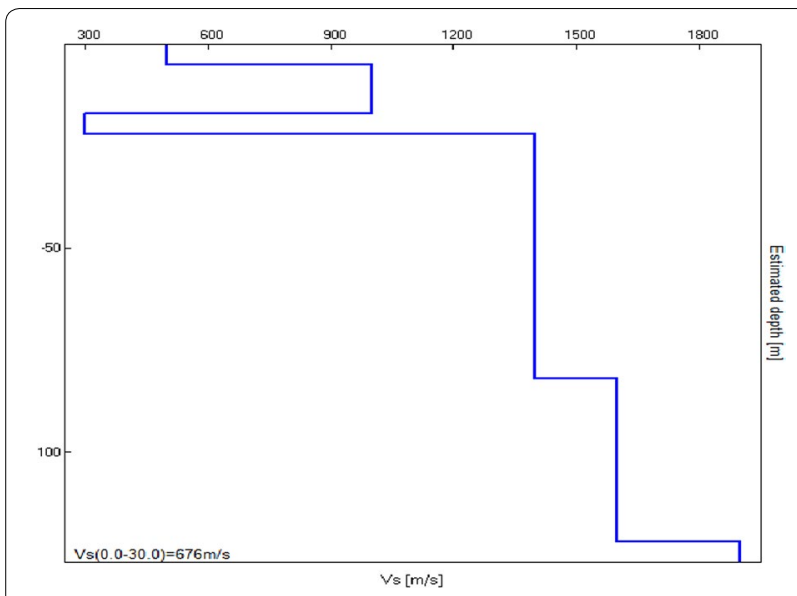

Fig. 6 Shear wave velocity profile at Santura Devi temple area, Mussoorie

Table 2 Results of MASW at Santura Devi temple area, Mussoorie

\begin{tabular}{llc}
\hline Depth at the bottom of the layer $(\mathbf{m})$ & Thickness $(\mathbf{m})$ & $\boldsymbol{V}_{\mathbf{s}}(\mathbf{m} / \mathbf{s})$ \\
\hline 5.00 & 5.00 & 500 \\
17.00 & 12.00 & 1000 \\
22.00 & 5.00 & 300 \\
82.00 & 60.00 & 1400 \\
122.00 & 40.00 & 1600 \\
Inf. & Inf. & 1900 \\
\hline
\end{tabular}

(Anbazhagan and Sitharam 2009) or corresponds to Site Class B and above in NEHRP site classification. The shear wave velocity in an intact rock (geological bedrock) is expected to exceed $1000 \mathrm{~m} / \mathrm{s}$ (Miller et al. 1999).

If we try to comprehend the results of both GPR and MASW simultaneously, some very interesting observations will come up. The subsurface imaging provided by the GPR survey clearly indicates that there exists an inclined soil layer between 0 and $24 \mathrm{~m}$ depths from the surface. The MASW results show a very weak layer $\left(V_{\mathrm{s}} \sim 300 \mathrm{~m} / \mathrm{s}\right)$ of $5 \mathrm{~m}$ thickness between 17 and $22 \mathrm{~m}$. The sudden drop in shear wave velocity can be attributed to the layer inclination here. And the immediate next to the inclined layer, a very high rise in shear wave velocity has been recorded. This value of shear wave velocity corresponds to hard rock, which is subsequently estimated to be the bedrock by GPR survey as well. The findings of the study for this particular site demonstrate not only how complementary and conclusive both the geophysical methods are, but also provide significant information on local site conditions prevailing in the area. These data can be very useful in assessing the overall seismic risk of the area.

\section{Mansadevi Landslide, Haridwar, Uttarakhand}

At this site, GPR surveying was performed using 35 and $80 \mathrm{MHz}$ frequency antenna in bi-static staking (point) mode. The GPR results are shown in Fig. 7a, b. However, as compared to the second site, these results could not provide any conclusive evidence on bedrock depth. Here, data up to only $20 \mathrm{~m}$ could be processed. The resolution of the data set also seemed to be of inferior quality. The primary reason for such difference is the variation of the material properties at both sites. The moisture content of the underneath materials also proves to be a vital factor as discussed earlier. The GPR results show two distinct layers. Approximately up to $2 \mathrm{~m}$ from the ground surface, there exists a layer of very loose material (debris). Unfortunately, the GPR data could not provide much information on soil layering after that. Sass (2007) pointed out that under certain circumstances, there is a lack of radar wave reflection at the debris-bedrock interface. Two possible reasons have been put forward by him:

"- The bedrock surface does not necessarily cause a strong radar reflection if the $K^{\prime}$ (the real part of the dielectric constant) values of rock and debris are very similar.

- Internal debris structures, e.g. the interbedding of coarser and finer scree (thus, higher portion of fines and higher water content) may produce stronger contrasts in $K^{\prime}$ and thus, stronger reflections than the bedrock boundary."

The lithology of the Mansadevi landslide comprises conglomerate, sandstone and mudstone sequences. Due to its proximity to both MBT and MFT, the transitory stresses are expected to be very high here which leads to its fragile geomorphology. Thus, there is a higher probability that both the bedrock and debris will have more or less similar $K^{\prime}$ values and therefore any conclusive inference could not be drawn for this site.

To estimate the bedrock depth conclusively, MASW testing was performed at the same site. The 24-channel MASW setup was used. But again with this setup, only up to $46 \mathrm{~m}$ from the surface could be explored. The shear wave velocity profile of the site is shown in Fig. 8.

Table 3 summarizes the results of the MASW experiment at Mansadevi landslide, Haridwar.

The results show that no bedrock (either engineering or geological) could be detected here at this site, as $V_{\text {s }}$ does not exceed $760 \mathrm{~m} / \mathrm{s}$. Although for this particular site no conclusive evidence on bedrock depth could be drawn, both the methods provide fascinating vital information on the subsurface condition. GPR survey 


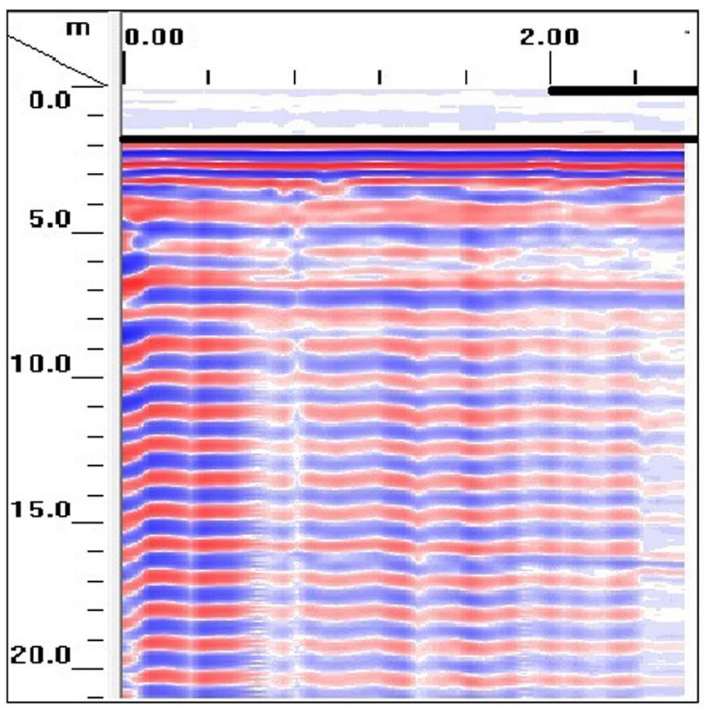

a

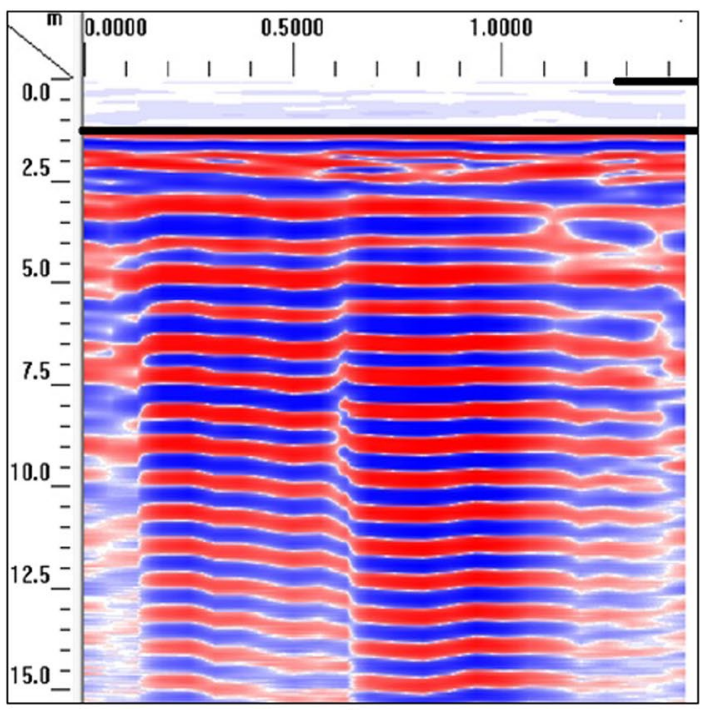

b

Fig. 7 GPR results at Mansadevi landslide area, Haridwar with a $80 \mathrm{MHz}$ and $\mathbf{b} 35 \mathrm{MHz}$ antenna

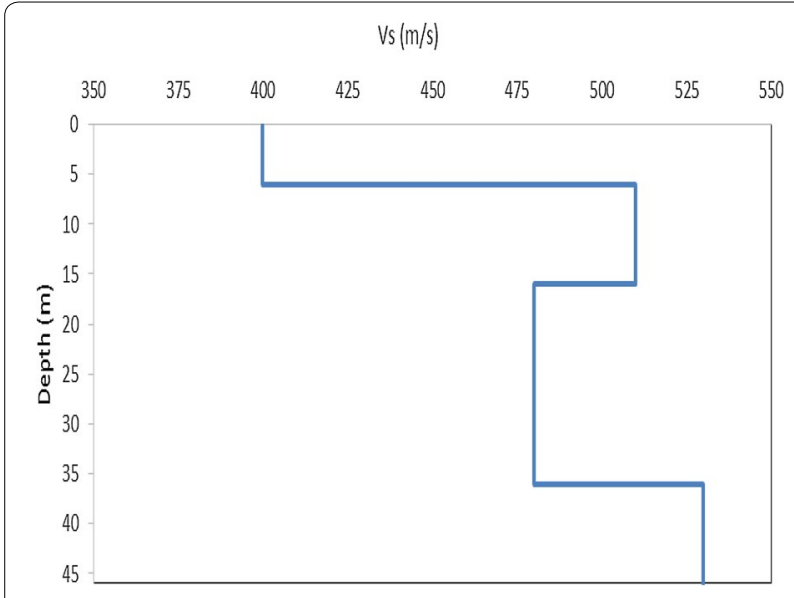

Fig. 8 Shear wave velocity profile at Mansadevi landslide, Haridwar

reveals that the top $2 \mathrm{~m}$ of soil is in a very loose state and thus can be considered as the debris of the landslide. The shear wave velocity profile obtained from MASW testing shows that the range of $V_{\mathrm{s}}$ lies between 400 and $530 \mathrm{~m} / \mathrm{s}$, which is somewhat less than the expected values in the region. The fragile geomorphology of the landslide which is underlined by highly jointed and fractured rock mass can be considered as the main factor for this. We also acknowledge the fact that the level of uncertainties remains high for the MASW results in this particular site, owing to its high gradients. Hence, a reduction of around $20 \%$ in shear wave velocity is recommended for the top layer of the site. Thus, a combination of test results obtained from GPR survey and MASW may be
Table 3 Results of MASW at Mansadevi landslide, Haridwar

\begin{tabular}{lcc}
\hline Depth at the bottom of the layer $(\mathbf{m})$ & Thickness $(\mathbf{m})$ & Vs $(\mathbf{m} / \mathbf{s})$ \\
\hline 6.00 & 6.00 & 400 \\
16.00 & 10.00 & 510 \\
35.00 & 19.00 & 480 \\
46.00 & 11.00 & 530 \\
\hline
\end{tabular}

very useful for any landslide study (primarily, for calculation of debris volume and understanding the internal structures). The local geology and the geo-morphological evidences when vetted against the results obtained led us to believe that for this site distinctive bedrocks do not exist at shallow depths.

As observed by Nath and Jakka (2012), bedrock depth can significantly alter the frequency content and amplification of the input motion. In general, shallower bedrock depth means very high amplification of input motions at higher frequencies $(>10 \mathrm{~Hz})$ and higher depth of bedrock will produce high amplification in lower frequencies $(1-3 \mathrm{~Hz})$. However, a number of factors, viz., the impedance contrast, soil layering and water table depth also play a major role in this highly intricate phenomenon. Combining two geophysical methods to estimate the bedrock depth has greatly contributed to the credibility of the results, as can been seen for the first site. Even when bedrock depth could not be estimated precisely for the second site, vital information on the local site conditions could be extracted from this study. 


\section{Conclusions}

The main aim of the present study is to estimate the depth of bedrock in a part of Garhwal Himalaya. Two different sites of Uttarakhand, India, with different geological attributes were selected. GPR and MASW experiments have been performed on both the sites and results obtained are combined to arrive at concurrent conclusions. For one site, a conclusive inference on bedrock depth could be drawn, whereas for the other site vital information regarding subsurface geology could be extracted. The study clearly demonstrates that it is feasible to combine the results obtained through more than one geophysical technique for subsurface exploration. Although both GPR and MASW provide two different genres of information, they can be combined effectively for comprehending the local site conditions. Each geophysical technique has its own merits and demerits and proper attention should be paid before finalizing the selection of a particular technique. This problem may be averted by selecting two or more methods together.

\section{Authors' contributions}

RRN and GK carried out the field experiments. RRN and MLS decided on the methodology. RRN and SCG carried out the observation. All authors discussed the results obtained and drafted the manuscript in corporation. All authors read and approved the final manuscript.

\section{Acknowledgements}

The authors would like to acknowledge the help of Mr. Sanjeev Astval and Mr. Anuj Gaur, Lab Assistants, Earthquake Engineering Department, IIT Roorkee, during the field visits.

\section{Competing interests}

The authors declare that they have no competing interests.

\section{Availability of data and materials}

The data set generated for the study area is available from the corresponding author on reasonable request.

\section{Ethics approval and consent to participate}

Not applicable.

\section{Funding}

Not applicable.

\section{Publisher's Note}

Springer Nature remains neutral with regard to jurisdictional claims in published maps and institutional affiliations.

Received: 2 September 2017 Accepted: 26 February 2018

Published online: 07 March 2018

\section{References}

Anbazhagan P, Sitharam TG (2009) Spatial variability of the depth of weathered and engineering bedrock using multichannel analysis of surface wave method. Pure Appl Geophys 166(3):409-428

Bard PY (1995) Effects of surface geology on ground motion: recent results and remaining issues. In: Proc. of the 10th European conference on earthquake engineering, Vienna, pp 305-323

Bichler A, Bobrowsky P, Best M, Douma M, Hunter J, Calvert T, Burns R (2004) Three-dimensional mapping of a landslide using a multi-geophysical approach: the Quesnel Forks landslide. Landslides 1:29-40
Boore DM (2004) Estimating $V_{s}(30)$ (or NEHRP site classes) from shallow velocity models (Depths<30 m). Bull Seismol Soc Am 94(2):591-597

Bristow CS, Jol HM (2003) GPR in sediments: advice on data collection, basic processing and interpretation, a good practice guide. Geol Soc Lond 211(1):9-27

Fisher CS, Stewart RR, Jol HM (2000) Processing ground penetrating radar. In: Proceedings of eighth international conference on ground penetrating radar, vol. 4084. University of Queensland, Australia, SPIE

Hauck C (2001) Geophysical methods for detecting permafrost in high mountains. Hydrol Glaciol 36(123):151-158

Hoffmann T, Schrott L (2002) Modeling sediment thickness and rockwall retreat in an Alpine valley using 2D-seismic refraction (Reintal, Bavarian Alps). ZeitschriftfürGeomorphologie 127:153-173

Israil M, Pachauri AK (2003) Geophysical characterization of a landslide site in the Himalayan foothill region. J Asian Earth Sci 22:253-263

Joshi A, Mohan K (2010) Expected peak ground acceleration in Uttarakhand Himalaya, India region from a deterministic hazard model. Nat Hazards 52(2):299-317

Mahajan AK, Galiana-Merino JJ, Lindholm C, Arora BR, Mundepi AK, Rai N, Chauhan N (2011) Characterization of the sedimentary cover at the Himalayan foothills using active and passive seismic techniques. J Appl Geophys 73(3):196-206

Miller RD, Xia J, Park CB, Ivanov JM (1999) Multichannel analysis of surface waves to map bedrock. Lead Edge 18(12):1392-1396

Mittal SK, Singh M, Kapur P, Sharma BK, Shamshi MA (2008) Design and development of instrumentation network for landslide monitoring and issue an early warning. J Sci Ind Res 67(5):361-365

Motoyuki (2001) GPR and its application to environmental study. Tohoku University, Sendai

Muzammil M (2013) Influence of pile geometry on the dynamic response of under-reamed piles. Department of Earthquake Engineering, Indian Institute of Technology Roorkee, Roorkee

Nath RR, Jakka RS (2012) Effect of bed rock depth on site characterization and seismic amplification. Paper presented at 15th world conference on earthquake engineering, Lisbon, 24-28 September 2012

Nath SK, Thingbaijam KKS (2012) Probabilistic seismic hazard assessment of India. Seismol Res Lett 83(1):135-149

Nath R, Hussain M, Jakka R (2015) Effect of bedrock depth on site amplification: a parametric study for different soil types. Int J Earthq Eng Hazard Mitig (IREHM) 3(2):29-36

Neal A (2004) Ground-penetrating radar and its use in Sedimentology: principles, problems and progress. Earth Sci Rev 66:261-330

Pal S, Keniya AM, Bhasin R, Paul DK (2012) Earthquake stability analysis of rock slopes: a case study. Rock Mech Rock Eng 45(2):205-215

Pandey B, Jakka RS, Kumar A (2016) Influence of local site conditions on strong ground motion characteristics at Tarai region of Uttarakhand, India. Nat Hazards 81(2):1073-1089

Park CB, Miller RD, Xia J (1999) Multichannel analysis of surface waves. Geophysics 64(3):800-808

Patil NS, Das J, Kumar A, Rout MM, Das R (2014) Probabilistic seismic hazard assessment of Himachal Pradesh and adjoining regions. J Earth Syst Sci 123(1):49-62

Pilecki Z, Isakow Z, Czarny R, Pilecka E, Harba P, Barnaś M (2017) Capabilities of seismic and georadar 2D/3D imaging of shallow subsurface of transport route using the Seismobile system. J Appl Geophys 143:31-41

Sass O (2007) Bedrock detection and talus thickness assessment in the European Alps using geophysical methods. J Appl Geophys 62:254-269

Schrott L, Saas O (2007) Application of field geophysics in geomorphology: advances and limitation exemplified by case studies. Geomorphology 93:55-73

SchSrott L, Hufschmidt G, Hankammer M, Hoffmann T, Dikau R (2003) Spatial distribution of sediment storage types and quantification of valley fill deposits in an upper Alpine basin, Reintal, Bavarian Alps, Germany. Geomorphology 55:45-63

Sitharam TG, Anbazhagan P (2006) Measurements of dynamic properties and soil profiling using multichannel analysis of surface waves. Invited Keynote in 4th Karl Terzaghi memorial workshops, vol 6

Van Dam RL (2012) Landform characterization using geophysics_recent advances, applications, and emerging tools. Geomorphology 137:57-73 